\title{
A Study on Teaching Behavior of Foreign Teachers and Their Roles in Classes in K12 English Language Teaching
}

\author{
Huimin $\mathrm{Zhu}^{1 *}$ \\ ${ }^{1}$ Faculty of English Language and Culture, Guangdong University of Foreign Studies South China Business College, \\ Guangzhou, 510545, China \\ *Corresponding Author's Email: anna_abroad@163.com
}

\begin{abstract}
For second language learners, foreign teachers play a significant role in the English language teaching (ELT) classes and English activities in China. The roles of foreign teachers are divided into four categories according to the author's observation of various classes given by foreign teachers as follows: the trigger, the supplier of an immersive environment, the presenter of educational thinking of the targeted language and the catalyst of the culture of the targeted language. At the same time, this paper also proposes two suggestions for foreign teachers based on realities, and aims to describe a perfect image of the foreign teacher.
\end{abstract}

Keywords: foreign teacher teaching,, ELT, L2 acquisition, acculturation theory

\section{INTRODUCTION}

\subsection{Second language acquisition}

\subsubsection{The Krashen Hypothesis}

Krashen (1985) proposed five hypotheses of the second language, including the Acquisition-Learning Hypothesis, the Monitor Hypothesis, the Input Hypothesis, the Affective Filter Hypothesis, and the Natural Order Hypothesis. [3]

These five hypotheses correlate with and are complementary to each other, forming an organic whole. The Krashen Hypothesis believes that acquisition and learning are two independent processes that differ in many aspects, such as psychological processes, the environment where they occur, the nature of knowledge and the storage of knowledge in the brain, and that the two cannot transform from one to the other. " Comprehension is a necessary but not the only condition of language acquisition." (Krashen, 1980). The hypothesis holds the view that learners' psychological issues prevent them from making the most use of the language input they receive during their language acquisition, a barrier known as affective filter. It is caused by learners' lack of motivation and confidence, or by anxiety. And the affective filter will have a direct bearing on learners' acceptance and processing of language materials.

Domestic scholars have made many researches on the Krashen Hypothesis. Wang Yanchao (2014) systematically concluded the relevant findings on the Krashen Hypothesis since the 1980s in China. The trend of the research has gradually transformed from theoretical research to teaching practice research; then to the research which focuses on a specific issue, and combines different theories. However, there have been fewer researches on which role in the roles and decisions of foreign teachers embodies the Krashen input hypothesis and the affective filter hypothesis, and on their impact on second language learners. Therefore, this paper attempts to fill this blank from the perspective of foreign teachers' teaching combined with the Krashen acquisition-learning hypothesis and the affective filter hypothesis. Guo Zhen (2014) [4] also concluded several inspirations that foreign teachers can continue to improve in English teaching in China by combining his personal experience in domestic high schools, universities and overseas learning programs in this course in the US. First, foreign teachers should have more knowledge of the Chinese culture, especially its impact on Chinese students' performance in the class. Second, they can add the introduction of cultural backgrounds of relevant 
English-speaking countries which are unfamiliar to students but helpful for English learning.

\subsubsection{Acculturation}

The psychologist Berry (1992) believed that the complete concept of acculturation should include two levels, one at the culture or community level, and the other at the psychological or individual level. According to Sun Jin (2010), acculturation can be understood as a state, or a process. Schumann (1986) believed that second language learners can only realize language acquisition at their corresponding level of acculturation. That is to say, the extent to which a second language learner acquires a second language is related to the degree to which he or she adapts to the culture of the targeted language. In general, "acculturation" refers to learners' social and psychological adaptation to the targeted language culture, i.e., whether the learner can integrate into the targeted language community socially and psychologically. Culhane (2014) pointed out the acculturation model of second language learners is an important component of their motivation for language learning. Richard (2016) found in his research that the ability and extent of acculturation of second language learners affect their fluency in the targeted language and the frequency of using the targeted language in the context. Besides, second language learners who are more highly adapted to the targeted language tend to show more confidence in learning.

Xiao Liming (1996) chose the first class of technical English majored students in Central South University of Technology as the research subjects to prove the effect of Schumann's theory of "acculturation model" on foreign language learning. He found that the subjects had an obvious improvement in English grades and performance through strengthening the education of socially explicit concept in the "acculturation model" theory. Therefore, it can be concluded that the society-led model indeed exerts an important impact on foreign language learning. Zheng Daihua (2017) divided the subjects into English-speaking group, English-Chinese group, and Hong Kong-Chinese group according to four factors, including their nationalities and family languages. He found that all three groups differed in social and psychological distance, which was positively correlated with their fluency in English. It is in line with the acculturation model by Schumann, that the language fluency of the second language learner depends on his or her social distance and psychological distance between the targeted language community.

\subsection{The roles of language teachers in the class}

Hammadou and Berhardt (1987, p. 302) put forward five teaching roles of foreign language teachers as follows:
(1) The unity of the teaching process and the teaching results. The teaching language and activities involved in the teaching process is language knowledge itself for foreign language learners.

(2) The medium of language use.

(3) The builder of a communicative environment. The core of the teaching purpose is to help learners communicate in the targeted language. Therefore, the focus of teaching is not on the objective language knowledge, but on helping learners communicate in the targeted language accurately and appropriately. So foreign language teachers shoulder the great responsibility of building the communicative environment in the class.

(4) Attaching importance to both the classes and extracurricular activities. In order to launch effective teaching, foreign language teachers must seek ways to provide extracurricular activities, through which they can create a natural learning environment.[1]

To sum up, unlike other teachers, language teachers take on other roles in teaching in the class. Based on the Krashen hypothesis of the second language acquisition and the Berry's acculturation model, it can be preliminarily inferred that the most two important roles of language teachers in teaching are language inputter and the instructor of the targeted language culture. While how foreign teachers (teachers with an international background of the targeted language culture) to further practice the above roles in English language teaching is the focus of the following discussion in this paper.

\section{FOUR ROLES OF FOREIGN TEACHERS IN ENGLISH LANGUAGE TEACHING}

\subsection{Language trigger}

For one thing, they are the language trigger in the class. First, the teacher and the learner must communicate in the targeted language, i.e., the English. Learners should respond quickly in the targeted language during the face-to-face communications, rather than through a series of complex procedures including translating the Chinese into the targeted language after their thinking. The communication initiated by foreign teachers can strengthen the learner's ability to think. While in oder to get closer to teachers, the communication triggered by the learner enables him or her to think how to communicate in the targeted language before the communication, fully making use of the acquired language structures and usages. Therefore, the ability to organize language in the mind is enhanced. Second, when explaining relatively obscure words, structures and grammars, foreign teachers often adopt the paraphrase which explains the English in English due to their own limited Chinese level. That is to say that they use relevant targeted language to describe the difficult points. For example, when giving an 
explanation of the word "plane", foreign teachers explain as "a kind of transportation that flies in the sky, usually used under a long distance; for example, from China to America, we need to take the plane"。

For another, they are the language trigger after the class. The foreign teacher is more like an alarming bell in the targeted language for learners. Their communication can only be initiated in English and it's almost impossible for them to communicate in Chinese. It is unnecessary to forcefully require or remind learners before they realize that they need communicate in the targeted language. During the extracurricular time, most Chinese teachers greet and communicate with children in Chinese, i.e. their mother tongue, while under such a circumstance there is often a power distance between them and children. While foreign teachers often maintain a close bond with learners, thus increasing the opportunities for learners to use the targeted language. When running into language problems, learners tend to turn to the foreign teachers. It is because learners are more convinced by the answers of the native speakers of the targeted language psychologically, and believe that they are more authoritative. And foreign teachers often add some of the most idiomatic and mostly used words and phrases to help learners grasp the knowledge.

\subsection{Providing an immersive environment}

For one thing, foreign teachers provide an immersive environment for learners, where the teaching language, the language of the textbook and the language of communication are all in English. A zero exposure to the Chinese - students' mother tongue, builds an immersive learning environment to learn the targeted language to some extent, allowing students to receive the same education as that in classes abroad, and restoring every aspect of the targeted language teaching to the largest degree. At the time, the foreign teacher can directly deliver information to learners, who then store the English information in their minds directly. Such a process can effectively avoid the negative transfer of the mother tongue caused by translation-meaning that learners use the expressions from their mother tongue when communicating.

For example:

Teacher : Thanks a lot. That's a great help.

Student : Never mind.

When a teacher praises a student for doing a good job, the student wants to say "Never mind." While in English the reply should be expressed in "You are welcome" or "It's my pleasure". But under the influence of Chinese, the learner misuses the expression used to forgive others in English.
For another, the foreign teachers provide an immersive cultural environment for the learners. L2 acquisition is a vibrant and busy field of inquiry.[6]From the perspective of the teaching thinking, instructional thinking, and encouragement patterns, all these are unconscious behaviors under the influence of their cultural backgrounds. For example, when Chinese teachers unconsciously say " Class begins!", foreign students often feel it is different from their own language teaching models, and then classify it as a Chinese teaching culture. And compared with the Chinese teacher's class, the class given by a foreign teacher enjoys a more lively atmosphere and a more diversified teaching model, which are all attributed to the foreign teacher's personality fostered in the context of his or her own cultural environment. And such personality forms teacher support. And the emotional experience of second language learners affects their performance, which is known as academic emotions. Many empirical studies have shown that students with more teacher support have higher PAEs or lower NAEs. Specifically, students with more teacher support have more enjoyment, interest, hope, pride, or relief (PAEs); or less anxiety, depression, shame, anger, worry, boredom, or hopelessness (NAEs) (Ahmed et al., 2010; King et al., 2012; Tian et al., 2013)[2]. Therefore, the teaching model used by foreign teachers often places less pressure on learners than that of the Chinese teachers, and has a more relaxed atmosphere and is less disciplined, making learners play freely.

\subsection{The presenter of the teaching thinking of the targeted language}

According to the acquisition-learning hypothesis proposed by Krashen (1985), the acquisition is the result of unconscious, subtle, and natural communications in the context of language. Therefore, it is particularly important to create a language environment in the teaching process. The experiential teaching, different from traditional teaching methods, aims to set up some concrete contexts where students are allowed to reorganize what they have learned and absorbed from the material and give an output in a new language environment after receiving a certain amount of input, and to increase students' language skills through the "input-understanding-absorption-reorganization-output" model. Compared with the Chinese teachers, the unique encouraging and rewarding teaching menthod foreign teachers foster in the context of the targeted language can better protect the language ego of the second language learners, allow them to make language mistakes fearlessly, so as to make greater progress while finding them. It can often be heard in classes held by foreign teachers that "who can have a try?", which also emphasizes that the experiential method helps second language learners build a bridge between input and output. 
As the presenter of the targeted language, foreign teachers often give more lively and relaxed classes. Krashen pointed out in the affective filter hypothesis that the affective variables are directly related to the second language acquisition. When conducting the second language teaching, foreign teachers should pay attention to students' emotions, and change teaching methods according to students' different emotions, and adopt more flexible measures for emotional factors such as confidence, frustration and the sense of competition and so on which obviously have an effect on learning performance. [5] Therefore, a relaxed class atmosphere is conducive to reducing class stress, so as to reduce the affective filer of the second language learners, making them have a higher emotional acceptance of the targeted language and have more knowledge of language.

The teacher-student relationship is more likely to be a friend to the child, allowing them to acquire the language unconsciously. The more you communicate in a language that the child can understand, the more comprehensible the input is, the better the acquisition is.

\subsection{The catalytic agent of the targeted language culture}

The acculturation theory believes that the acculturation depends on two factors including social distance and psychological distance, and its process determines the process of the second language acquisition. The closer the psychological distance and the social distance between the learner and the targeted language culture, the higher the degree of acculturation of the learner. Therefore, learners can better learn the targeted language.

First, As a sign of the targeted language culture, the foreign teacher's class has already been cultural to the second language learners, so as to narrow the distance between them and the targeted language culture.

Second, During the teaching process, foreign teachers more frequently base their teachings on their own backgrounds, such as telling stories and saying idioms of the targeted language. They can naturally give an cultural education while teaching language. For example, "raining cats and dogs" is a common idiom, meaning "raining heavily", or they intersperse their own growing experiences in their teachings to enable students have more access to real language materials, which are more interesting than those in textbooks.

Third, Foreign teachers dominate the extracurricular activities, and have a significant role in enriching students' second class. For example, foreign teachers are often invited to be the judges of English competitions, or be a guest performer in musical or drama festivals, hold some lectures to introduce western culture, customs and traditions to students to enable the second language learners to have a further understanding of the distinctive cultures of English-speaking countries.

\section{CONCLUSION}

Based on theories related to second language acquisition and the acculturation theory, this paper portrays a perfect foreign teacher in English language teaching, that a foreign teacher should play four roles in the second language teaching class, namely, as a trigger, a supplier of an immersive environment, a presenter of the thinking ideology of the targeted language and a catalyst of the targeted language culture. Through the comparisons and observations of the actual classes given by the foreign teachers, it can be found that the foreign teacher plays well his four roles. While he still need to make corresponding adjustments in the context of China's realities in terms of the teaching thinking. For example, in the face of learners who are too young, the foreign teacher should change the thoughts as appropriate, and carry out subsequent exercises before making sure students have understood and mastered the knowledge, instead of just catching up. In the face of a class where students perform unevenly, it is necessary for the foreign teacher to find out in time and carry out measures such as after-class assistance or class shifts, otherwise students with lower learning abilities will be left behind, perform even worse, and grow sick of the second language acquisition. Therefore, it is remarkably important to pay attention to students' mastery of the teaching content. And teachers should adjust their teaching plans in time according to students' homework and class performance to make sure students truly understand the knowledge, which will enable students to benefit more from English language teaching given by foreign teachers. All in all, these are the description of the perfect foreign teacher image and suggestions made after the filed investigation.

\section{REFERENCES}

[1] Yeşim Betül OKTAY, Ülker VANCI OSAM. VIEWING FOREIGN LANGUAGE TEACHERS' ROLES THROUGH THE EYES OF TEACHERS AND STUDENTS. Hacettepe Üniversitesi Eğitim Fakültesi Dergisi [H. U. Journal of Education] 44: 249-261 [2013].

[2] Ahmed, W., Minnaert, A., van der Werf, G., and Kuyper, H. (2010). Perceived social support and early adolescents' achievement: the mediational roles of motivational beliefs and emotions. J. Youth Adolescence. 39, 36-46. doi: 10.1007/s10964-0089367-7. 
[3] Stephen D. Krashen. Principles and Practice of Second Language Acquisition. Pergamon Institute of English. Pergamon Press. 1982.

[4] Guo Zhen." The Enlightenment of Second Language Acquisition Theory on English Teaching of Foreign Teachers in China. Overseas English 000.004(2014):35-38.

[5] Li Luliang." On the Enlightenment of Krashen second Language Acquisition Theory to College English Teaching." Educational Theory and Practice 38.33(2018):60-61.

[6] Bill VanPatten, Megan Smith, Alessandro Benati. Key Questions in Second Language Acquisition: An Introduction. Camberidge University Press. Nov 27th 2019, P46. 